\title{
Islands Apart: Leadership Studies in Two Island States
}

by Jennie Billot

\begin{abstract}
School leadership is situated within a context of social and political factors that work to distribute power while also holding it in check. There are connections between how societal political structures facilitate democratic participation and the operation of schools. Educational leadership straddles the interface between proactive agency and the politics of social control. This tension between holding and using authority, yet acceding to political and social practice, is one which many school leaders face.

Research studies conducted in two island nations, Jersey (Channel Islands) and Tonga (Pacific Islands), in different hemispheres of the world, illustrated contrasting forms of educational service and different challenges for school principals. As island communities, the context was clearly definable and provided a set of variables that were manifested through sector processes. The principals held pivotal roles that were molded by the contextual factors which shaped the delivery of educational practice. School principals in Jersey and Tonga illustrated how leadership is complicated if the purposes leadership should serve are unclear or contested (O’Brien, Murphy, and Draper 2003).
\end{abstract}

There are worldwide similarities in how educational systems operate, and research has shown that educational leaders around the world face similar challenges (Cranston 2000; Wildy and Louden 2000). However, in a period where international linkages contribute to a global community, there are some localized groups hastening to reassert their particularity. Island communities are one example of such groups.

This paper examines how communities defined by obvious natural boundaries may experience a strong sense of identity in social values, loyalties, and cultural meanings that contrasts with those of their neighbors (Lui 1996). This can result in social repercussions that impact the positioning of educational leadership. This paper focuses on a specific context - that of small island states, specifically Jersey (United Kingdom) and the Kingdom of Tonga. From observations during intensive studies (Billot 2003a, 2003b, 2003c; Cranston, Ehrich, and Billot 2003), there appeared to be 
additional factors that contributed to the challenges that school principals in these islands encounter. Research conducted in New Zealand, Jersey, and Tonga and comparisons made with research conducted in Queensland (in Cranston, Ehrich, and Billot 2003) pointed out that principals contend with a number of issues that are germane to being a principal and differ only in degree. In interactions with the educational sectors in Jersey and Tonga, it became evident, however, that there were additional peculiarities of principalship that can be ascribed to the contexts of these islands.

Island territories are bounded communities_-distinct and separate, yet linked to other nations by historical, social, and economic ties. Unravelling how a principal on an island deals with educational leadership challenges that exist within the inward focus of insularity is difficult. An island psyche underpins the identity of the community and though autonomy is possible, insularity treasured, and culture guarded, how is it possible to be bounded totally and yet be an integral part of the global environment?

The impact of scale is emphasized in this paper. The term "island" is used to refer to those nations that are distinct, yet small (as used by Ribbins, Pashiardis, and Gronn 2003 in their discussion of the four small islands of Hong Kong, Cyprus, Malta, and Singapore). Obviously, there are some large nations of the world which are islands, such as Australia and Britain, but the intent is to focus on those that are of a significantly small scale. Gronn and Ribbins $(2003,76)$ identified a "quest to recapture a sense of community" through a reversion to smallness that began in the 1960s and '70s when "one offshoot of the cultural revolution which began transforming Western social values was a growing acceptance of the virtue of smallness.”

The term "community" is used to refer to those groups of people who inhabit their own islands. A useful, common definition of community is "a group of people living together in one locality, having common interests, goals, and customs, and having a system of values that is shared and commonly understood among its members” (Chud 1998, 57). A “neighborhood/community” also can be viewed as supplying a vehicle for emotional needs such as fraternity, identity, and sociability (Chud 1998; Cater and Jones 1989; Strike 1999; Taylor, Watts, and Johnston 1995). These definitions apply to communities at large, but are particularly applicable to islands that aim for accessibility at a human level. Harington $(1997,18)$ believed that 
the "community is a strategy to remind us that human scale is important and indeed critical.”

Jersey is the largest of a group of islands known as the Channel Islands, off the southern coast of England, but nearer in distance to the Brittany coast of France. The second island state, the Kingdom of Tonga, is in the southern hemisphere, positioned with many other island states in the Pacific Ocean. The two island territories have a similarly constructed national identity, but very different social histories and value systems. There are similarities in modes of social control which impact the education sector. Within the education sector, there are interesting parallels of leadership though the contexts are disparate.

The school principals in both locations have roles that are socially constructed in different ways, yet they face similar dilemmas. This may indicate the need to question the tensions that result due to the differences between the school leader role as defined by the state and that which is actually experienced by principals. Are these tensions the result of being located within an island society or the result of more generic structures?

The particularity of island context contributes to how island leadership is framed, facilitated, and constrained. The physical boundaries of islands create not only a bounded entity in which society is structured, but a recursive dynamic between physical boundaries and social and cultural characteristics. The cultural and social imperatives appear to bounce off the physical boundaries which then reflect back, amplify, and reinforce those features that determine the island's identity.

\section{Case Studies}

Jersey. The island of Jersey has a population of around 88,000 people. Though the United Kingdom has diversity of regions and community groupings, Jersey has its own particular identity and is a unique locality. It remains outside of the EU (what does this acronym stand for?) and has very distinct French influences due to its history. The island is self-governing, though it is ruled under the sovereignty of the current Queen of England.

Jersey has developed its own structure for educational changes which focuses on retaining its insularity. Its commitment to produce "well-educated, well-trained, and well-qualified personnel that provide the island with an effective and efficient workforce, thus minimizing the demand for labour from external sources” (States of 
Jersey Policy and Resources Committee 2001, 11) is indicative of its desire to remain distinct. Education delivery is the responsibility of the Education Department which carries out the functions on behalf of the Education Committee under the jurisdiction of the States of Jersey.

Though Jersey has not adopted a fully delegated, school-based management model, principals are required to take on managerial roles and assume many functions that might have been done previously at a systemic level. Specifically, the day-to-day management of the school and policy implementation is the responsibility of the principal. Jersey currently operates within a system of delegated financial management which provides the freedom for principals to make decisions on curriculum and school management, but within significant controls exercised by the Education Committee. The United Kingdom's national curriculum is not followed by law, but has been accepted as community policy with local variations integrated.

The principal in concert with the school's Governing Body-a corporate body in Jersey law that is responsible for policy development and delivery within the Committee framework - agree on the aims, values, ethos, and priorities of the school. At the same time, there is commitment to the concept of community through an Education Department policy (States of Jersey Education 1999, 20) that "seeks to promote Jersey's own heritage and culture and enhance the sense of community.” The school is accepted as one of the community's major influencing factors and the center of community activity (States of Jersey Education 1999; Wylie 1999). This role is reinforced by the Director of Education who believes that the two most important elements of the principalship are leadership and strong interpersonal skills (Billot 2003a).

Principals in Jersey also must be able to look beyond their own school unit to the larger picture of island education. Acknowledging this requirement, the Director (Billot 2003a) defined the role of principal as "someone who is concerned about the health of the whole system,” emphasizing the need for the school principal to maintain a recursive relationship between school processes and the States of Jersey vision.

Tonga. The Kingdom of Tonga, like every other island group in the Pacific, has "a wealth of indigenous wisdom embedded in its unique cultural legacy” (Hezel 1992, 63). It is an independent kingdom of 150 islands (of which only 36 are 
inhabited) with a total population of more than 97,000 people. Tonga is a constitutional monarchy with a king as head of state despite sovereignty of the nation state being undermined by globalization (Holton 1998). Tonga lies at "the confluence of traditions, local and Western” (Hezel 1992, 67) and, as in much of the Pacific where society is highly aristocratic and nonegalitarian (Hassall 1992), Tonga society is highly and rigidly stratified (Hoponoa 1992) and reinforced by traditional moralities.

In his program of reform, King Taufa' ahau Tupou IV opened up Tonga to the world by modernizing its economic sector. In doing so, he made the country more vulnerable to external social, economic, and political influences (Hoponoa 1992). It is perhaps the only ethnic nation residing in one state that both precedes and follows the colonial period. This has undoubtedly had a bearing on its approach to constitutional monarchy (Hassall 1992). Though Tonga continues to have a traditional ruler as head of state, pressure is mounting on King Tupou to introduce a more democratic electoral system through political and constitutional reform.

The process of education delivery is the responsibility of the Ministry of Education whose mission for the next decade is "to provide and sustain lifelong, relevant, and quality education for all Tongans” (Ministry of Education 2000, 2). The administration of Tonga's educational system is highly centralized, with decisions made by the Minister of Education and responsibilities for education shared by government and nongovernment (mainly religious) organizations (Ministry of Education 2000). The majority of secondary students study in nongovernment schools while more than 90 percent of primary school children are educated in government schools. Principals have roles that differ according to their funding agency (government or nongovernment) which determine their levels of independence and accountability.

Though Tonga has not adopted a delegated school-based management model, principals are required to take on managerial roles and assume functions that might have been done previously at a systemic level. Incorporated in the strong centralized control and direction from the Ministry is a demand for complete loyalty to the Tongan rule. Consequently, the principal performs a critical role in providing leadership for the school while looking at the larger picture of Tongan education.

\section{Island Identity}


What causes islands such as Tonga and Jersey to be distinct communities, and how distinct are they? Are the characteristics of being an island sufficient to define specificity? Living on an island and being part of a bounded community creates its own category for examination. It is the island culture that frames the peculiarities of island principalship. Johnston $(1993,25)$ stated:

One of the many ways in which people structure their lives is by defining boundaries and representing them in the landscape. Places with which they can identify help people to gain a sense of self-identity, safety, and security in an uncertain world.

If this is true, then islands provide obvious physical boundaries that help identify who are insiders and who are outsiders to the national territory. The resulting relationship between insiders creates contexts in which social practices develop. It is within this defined space that people can develop their personal identity. According to Massey (1991, 29), people have a need for attachment, whether through place or other aspects of their lives, for "the constellation of social relations weaving together at a particular locus constructs place's specificity, a meeting place. The specificity of place is continually reproduced.” Islands offer a conveniently defined entity in which this can occur. It is within islands that particular community cultures emerge and are sustained by internal social practices. This may seem to contradict Pawson $(1996,349)$ who described the "specificity of place as being the focus of a distinctive mixture of wider and more local social relations.” Though strongly bound to the national government and the trends occurring globally (Le Heron 1995; Massey 1994), island communities often retain a strong internal focus that maintains a proactive and self-renewing community (Miserandino 1998).

Apart from the nature of community in island states, other concepts that differentiate islands are the "local” and "local culture.” Local is seen as a cultural construct. Featherstone (1996, 47) explained:

Within the sociological tradition, the term local and its derivatives, locality and localism, have generally been associated with the notion of a particular bounded space with its close-knit social relationships based upon strong kinship ties and length of residence. 
There is usually an assumption of a stable, homogeneous, and integrated cultural identity that is both enduring and unique.

In addition, Featherstone $(1995,92)$ viewed "local culture” as a particularity that is opposite of global:

The sense of belonging, the common sedimented experiences and cultural forms which are associated with place, is crucial to the concept of a local culture, ( but) the drawing of a boundary around a particular space is a relational act which depends upon the figuration of significant other localities within which to situate it.

If culture is taken to mean the collective values, beliefs, and customs shared by a group, then its power as an analytical tool comes from the fact that "values and beliefs underpin organizational structures, processes, and practices which, in turn, are the essence of organisations and organisational behaviour” (Dimmock and Walker 1997, 386-87). Hall (1990, 226) pointed out that "cultural identities are the points of identification. Not an essence but a positioning.” Drawing these concepts together allows us to view islands as specific physical and social localities, with communities that have a bounded and particular cultural identity. Islanders form a community of difference through physical locality and community form, but also may retain diversity and differentiation and often conflict within that bounded entity.

This brief examination of the linkages between community and local culture may help to unravel the complexity of determining how an island sees itself as a nation. Islands, particularly those that are self-governing, easily create social frameworks that develop, support, and perpetuate the values and beliefs that maintain the island community as a cohesive unit. Because "space and place are essential components of social action” (Huxley 1986, 338), islands can offer compact societies in which the inhabitants facilitate a social system that strongly reflects their own character and focus. Though not all islands have historically had this flexibility, some have, such as Jersey and Tonga.

Though social science researchers have wrestled with delineating the boundaries of a locality/community, certain islands have successfully kept themselves apart from their geographical and political neighbors, retaining their autonomy and 
distinctiveness through their own social and political processes. Though Tonga and Jersey have strong links to lands outside their own borders and would not survive without regional and global participation, they illustrate a significant insularity. Featherstone (1996) saw this as the shifting of people’s consciousness to the collective and away from the individual.

Jersey and Tonga can be identified as particular island contexts—ones that perpetuate island identity and insularity through the "way things are done (Marx in Liu and Mackinnon 2002, 119). Thus the context for educational leadership is framed not just by the social and political system and the influence of other nations in terms of economic and policy-led initiatives, but also by the specific way in which islanders interact and act to maintain their national difference.

\section{Challenges for Island Educational Leadership}

Education is not a separate activity which occurs in isolation, but a means by which the community invests and engages in its development (States of Jersey Education 2002). Principals throughout the world act as mediators "between the 'outside' context and the 'inside' culture of the schools” (Retallick and Fink 2002, 102). Though this is true for all school leaders, being a principal in Jersey and Tonga has its own specific challenges, as prescribed and framed through island community identity and local culture.

Though the two islands are geographically many miles apart, the principals in those states face similar challenges related to the island context. Research on the principal's role in New Zealand and Australia identified challenges that principals in Jersey and Tonga face, such as the conflict between time spent on leadership and management. Gronn’s (1996) simple definition which identified two significant attributes that best define how leadership is exercised through influence and identification can be used to describe the leadership in Jersey and Tonga. In these states, there is an intrinsic emphasis on the role of principal as being not only reflective of the island culture and society, but also as influential in the transference of social and cultural norms and values. This may cause a conflict in their day-to-day roles which Retallick and Fink (2002) referred to as being part of the philosophical confusion of definitions of leadership.

The research conducted in Jersey and Tonga uncovered strong satisfaction in terms of the degree of pressure and workload. Neither pressure nor workload had 
increased noticeably within the last few years in either location. The principals' major concerns centered on the limited amount of time they had to dedicate to leadership. From their perspective, less time should be spent on management/administration issues. Though principals in both island states believed staffing issues were of great importance, there was an interesting contrast in the amount of time that should be spent on student issues, with Tonga emphasizing them more than Jersey.

The typical week for principals in Jersey and Tonga contrasted significantly with their ideal week, particularly in the balance between management and leadership. The ideal week viewed from a system perspective, or how the principals believed the Department/Ministry of Education would like them to spend their time, was different again. Principals believed that the Department/Ministry wanted a significant amount of time spent on management/administration, staffing matters, and strategic leadership.

The most significant problem expressed by the principals in Tonga, and to a lesser degree in Jersey, was the constraint encountered through strong centralized control of the principals' authority. The principals in both localities indicated that greater autonomy and flexibility in their roles could enhance the quality of their school leadership. An increased transparency of vision for education and a consistent approach to the empowerment of school principals also could help. They believed that, as professionals, they had the capacity to work at the interface of the school community, its stakeholders, and the Ministry in ways that hold island national identity as a core value. It was in this context that school leaders were challenged to "deal with the particular conglomeration of cultural circumstances in which they are located at any given time” (Gronn and Ribbins 2003, 92).

For the Department/Ministry of Education that shapes the role of the principal, there are significant opportunities to capitalize on the positive issues identified in this research. The high level of satisfaction among principals and their commitment to contribute toward healthy and sustainable societies in Jersey and Tonga provide a vehicle for addressing issues that constrain effective educational leadership.

Strategizing a solution that could ameliorate the principals' perceived constraints should not necessarily entail adopting policy or processes from outside the island states; rather a contextually framed solution is needed. Hallinger and Leithwood (1996) noted that, as education systems around the globe tend to reflect Western theories and practices with little consideration of their cultural fit, there is a 
danger of “policy cloning” (Dimmock and Walker 1997, 391) whereby policy makers adopt or imitate practices and processes that were developed in contextually dissimilar educational systems.

Some of the issues facing principals in Jersey and Tonga can be addressed usefully. For Jersey principals, the greatest concern was the integrity of the whole educational system with a need to define "what the island believes learning to be and then leadership for that learning, whether at the school, departmental, or political level.” An island educational system that identifies the balance between devolved responsibility and centralized control would acknowledge agency at the local level of implementation and avoid perceiving and implementing policy as a linear process. This would encourage confident, skilled, and well-supported leaders who can foster a sense of ownership and purpose in the way that teachers approach their jobs.

One Jersey principal expressed frustration:

When I consider the school, the part of the system I manage, I am not complacent but I am satisfied with the progress we are making. When I consider the system in which I work, I am constantly disappointed by the failure to grapple successfully with critically important issues we face.

Tonga is not exempt from the key issues identified within education in the Pacific during the 1980s and that still need to be addressed. Like many Pacific states (Thomas 1993, 242), Tonga is being pressured to debate "where authority is best placed to foster the efficient administration of education for their people while at the same time satisfying the political interests of local communities and of interested powers and religious denominations.”

Responses collected from Tongan principals suggested that policy makers need to be closer to those who implement policies. One principal suggested that "the process should be consultative by the decision makers . . . this is a way to achieve 510 year dreams.” This was witnessed by Larner $(1996,99)$ who acknowledged the leadership role as a "politics of affinity (that can be) based on shared purpose rather than common identity."

Because Jersey and Tonga operate as national entities rather than local authorities, there is a unique ability to determine locally the educational system for the 
island states. Therefore, being a principal involves responding to the demands of complex societal interrelationships that are constantly changing. Jersey and Tonga principals face no less a challenge than school leaders in other western countries. Their roles, however, reflect differing parameters, accountabilities, and constraints, and portray a uniqueness that is related to the particular island context. Each principal must assess their mode of response to an educational framework that both facilitates and constrains school leadership.

If more effective school leadership is to be achieved, it will entail change at the structural and social level. Islanders have an extraordinary capacity for change and adaptation (Nettleford in UNESCO 2003); however, the unique features of an island can help determine reform strategies (Ray 1999).

\section{Conclusion}

The island context is significant for educational leadership, because "scale is a crucial dimension for understanding social practices” (Taylor, Watts, and Johnston 1995, 378). Island states offer contexts in which principals negotiate community expectations, the learning needs of their students, and social and cultural constraints.

"Localities are not inert population aggregates, (but) are constituted of people and their social networks (Taylor, Watts, and Johnston 1995, 380). Islands offer examples of how bounded systems can constrain leadership. In Jersey and Tonga, the centralized control of education requires that as "schools reflect society" (Wylie 1999, 195), principals are responsible for transmitting constitutive beliefs and values which generate a conception of what is good education. It is through such values that people view themselves as working together, “underpin the concept of community,” (Strike 1999, 47) and are integral to island community identity. The principal is required to interpret and facilitate processes to achieve this.

The research supporting this paper strongly indicated that principals in Jersey and Tonga preferred more autonomy in facilitating their leadership. Their powers and authority were intertwined clearly with the politics of island /cultural containment and were sometimes obscure in the facilitation of a principal's daily role. Though Jersey seeks to maintain its separation from the "mainland” (the United Kingdom), Tonga holds change in check through strong religious and hierarchical control. A high level of central control and role definition (more obvious in Tonga) is a key feature of the educational system’s “centralized control of major educational policies” (Chew, Stott, 
and Boon 2003, 73). Another concern is whether islands "opt for outcomes which yield inflexible forms of institutional retention and which may be likely to produce cultural drift, stasis, or atrophy” (Gronn and Ribbins 2003, 82-83).

There may be a temptation to describe schools and schooling in different societies and draw conclusions on the basis of effective practice "without adequate recognition being given to cultural or contextual differences” (Dimmock and Walker 1997, 380). However, it is these differences that may have enormous implications in determining the appropriate patterns of leadership, management, and organization for schools in different societies. In reality though, how different are these two islands from their global counterparts? Though it is not possible to measure levels of difference, it is possible to identify points of difference and what they mean in specific locales. The connections between leadership and geographical and social environments influence and shape the pattern for principalship. For Jersey and Tonga, it is the bounded nature of the systems developed through island identity that sculpts the different ways of working as educational leaders.

The future challenge for islands that continue to assert their insularity and separateness is to provide a climate and platform for growth and change that reflect and support their points of difference. Island policy makers should make the most of positive input from principals. Their commitment toward a healthy and sustainable educational sector provides a vehicle for addressing those issues that constrain effective leadership. Context is everything and the way forward needs to be articulated by the State of Jersey and the Tongan Ministry.

To truly understand the nature of educational leadership on islands, one must develop "territorial knowledge (which) comes from fully situating pertinent actors and action in their geographic and historical context” (Le Heron 1995, 125). This is no less true for school leaders in island contexts where the principal's challenge is to negotiate the lattice of political, social, cultural, and religious factors that form the basis of their island's identity.

The research in Tonga (2003) was funded in collaboration with Commonwealth Council for Educational Administration and Management (CCEAM)) through the Commonwealth Foundation.

\section{References}


Billot, J. 2003a. Being a headteacher in an island state: A case study report on Jersey. Jersey, Channel Islands: Education Department.

Billot, J. 2003b. Being a principal in the Pacific: A case study report on Tonga. Cypress, Greece: CCEAM.

Billot, J. 2003c. The real and the ideal: The role and workload of secondary principals in New Zealand. International Studies in Educational Administration 31(1): 33-49.

Cater, J., and T. Jones. 1989. Social geography: An introduction to contemporary issues. London: Edward Arnold.

Chew, J., K. Stott, and Z. Boon. 2003. On Singapore: The making of secondary school principals. International Studies in Educational Administration 31(2): $54-75$.

Chud, H. 1998. Building school community. The Education Digest 63(5): 57-58.

Cranston, N. 2000. Changes for schools . . c changes for principals. The roles of primary principals under school based management. The Journal of the Queensland Association of State School Principals 26(4): 25-28.

Cranston, N., L. Ehrich, and J. Billot. 2003. The secondary school principalship in Australia and New Zealand: An investigation of changing roles. Leadership and Policy in Schools 2(3): 159-88.

Dimmock, C., and A. Walker. 1997. Toward comparative educational administration: Building the case for a cross-cultural school-based approach. Journal of Educational Administration 36(4): 379-401.

Featherstone, M. 1995. Undoing culture: Globalization, postmodernism, and identity. London: Sage.

Featherstone, M. 1996. Localism, globalism, and cultural identity. In Global/local: Cultural production and the transnational imaginary, ed. R. Wilson and W. Dissanayake, 46-77. Durham, NC: Duke University Press.

Gronn, P. 1996. From transactions to transformations: A new world order in the study of leadership? Educational Management and Administration 24(1): 7-30.

Gronn, P., and P. Ribbins. 2003. Evolving formations: The making of secondary school principals in selected small islands. International Studies in Educational Administration 31(2): 76-94.

Hall, S. 1990. Cultural identity and diaspora. In Identity: Community, culture, difference, ed. J. Rutherford, 222-37. London: Lawrence and Wishart. 
Hallinger, P., and K. Leithwood. 1996. Editorial. Journal of Educational Administration 34(5): 4-11.

Harington, P. 1997. Community: Language and ideology. In Community issues in New Zealand, ed. C. Bell, 17-33. Palmerston North, New Zealand: Dunmore Press.

Hassall, G. 1992. Renegotiating the social contract: Constititional change in the Pacific Islands. In Pacific history: Papers from the 8th Pacific History Association Conference, ed. D. H. Rubenstein, 73-95. Guam: University of Guam Press.

Hezel, F. 1992. Recolonizing islands and decolonizing history. In Pacific history: Papers from the 8th Pacific History Association Conference, ed. D. H. Rubenstein, 63-67. Guam: University of Guam Press.

Holton, R. J. 1998. Globalization and the nation-state. London: Macmillan Press. Hoponoa, L. 1992. Pro-democratic movement in Tonga: The case of Samiuela 'Akilisi Pohiva. In Pacific history: Papers from the 8th Pacific History Association Conference, ed. D. H. Rubenstein, 97-99. Guam: University of Guam Press.

Huxley, M. 1986. Planning practice and social theory: A guide to further reading. In Urban plannings in Australia: Critical readings, ed. J. B. McLoughlin and M. Huxley, 333-44. Melbourne, Australia: Longman.

Johnston, R. J. 1993. The challenge for geography: A changing world; a changing discipline. Oxford, UK: Blackwell Publishing.

Can't verify? Larner, W. 1996. Feminisation of the labour force. In Changing Places: New Zealand in the nineties, ed. R. Le Heron and E. Pawson, 97-101. Auckland, New Zealand: Longman Paul.

Le Heron, R. 1995. Territorial knowledges: Part of being an educated person in the future. Journal of Geography in Higher Education 19(2): 125-27.

Lui, L. 1996. Cultural identity and development in the Torres Strait Islands. New Delhi, India: Indira Gandhi National Centre for the Arts. Available at: http://ignca.nic.in/ls_03009.htm.

Liu, J., and A. Mackinnon. 2002. Comparative management practices and training: China and Europe. Journal of Management Development 21(2): 118-32. Massey, D. 1991. A global sense of place. Marxism Today June: 24-29. 
Massey, D. 1994. Space, place, and gender. Minneapolis: Polity Press and University of Minnesota Press.

Ministry of Education. 2000. Education for all: The year 2000 assessment. Country report by Tonga. Nukualofa, Tonga: Ministry of Education.

Miserandino, A. 1998. Institutionalizing a vision for diversity. Educational Horizons 76(3): 147-50.

O’Brien, J., D. Murphy, and J. Draper. 2003. Policy and practice in education. Edinburgh, Scotland: Dunedin Academic Press.

Pawson, E. 1996. Senses of place. In Changing Places: New Zealand in the nineties, ed. R. Le Heron and E. Pawson, 347-49. Auckland, New Zealand: Longman Paul.

Ray, B. 1999. Good governance, administrative reform, and socio-economic realities.

A South Pacific perspective. International Journal of Social Economics 26(1/2/3): 354-69.

Retallick, J., and D. Fink. 2002. Framing leadership: Contributions and impediments to educational change. International Journal in Education 5(2): 91-104.

Ribbins, P., P. Pashiardis, and P. Gronn. 2003. The making of secondary school principals on selected small islands: An introduction. International Studies in Educational Administration 31(2): 2-12.

Can't verify? States of Jersey Education. 1999. A five year strategy plan 1999-2004. Jersey: States of Jersey.

Can't verify? States of Jersey Education. 2002. Education Department: 2002 business plan. Jersey: States of Jersey.

States of Jersey Policy and Resources Committee. 2001. Jersey into the millennium: A sustainable future. Jersey: States of Jersey.

Strike, K. A. 1999. Can schools be communities? The tension between shared values and inclusion. Educational Administration Quarterly 35(1): 46-70.

Taylor, P. J., M. J. Watts, and R. J. Johnston. 1995. Remapping the world: What sort of map? What sort of world? In Geographies of global change: Remapping the world in the late twentieth century, ed. R. J. Johnston, P. J. Taylor, and M. J. Watts, 377-85. Oxford, UK: Blackwell Publishing.

Thomas, R. M. 1993. Education in the South Pacific: The context for development. Comparative Education 29(3): 233-48. 
United Nations Educational Scientific and Cultural Organization. 2003. Socio-cultural dimension of island development. Available at:

http://portal.unesco.org/en/ev.php$U R L \_I D=12135 \& U R L \_D O=D O \_T O P I C \& U R L \_S E C T I O N=201 . h t m l$.

Wildy, H., and W. Louden. 2000. School restructuring and the dilemmas of principals’ work. Educational Management Administration and Leadership. 28(2): 173-84.

Wylie, C. 1999. Ten years on: how schools view educational reform. Wellington: New Zealand Council for Educational Research.

Jennie Billot is a senior lecturer in postgraduate research methods, having worked across the education sector in teaching, research, evaluation, and reviewing. Her current research focuses on educational and ethical leadership, particularly the impact of social context on school leadership. 